19 *Corresponding author:

20 Pei-Ying Hong

21 Email: peiying.hong@kaust.edu.sa; Phone: +966-12-8082218

22 Thomas Missimer

23 Email:tmissimer@fgcu.edu; Phone: +1-239-7454538 Thuwal, 23955-6900, Saudi Arabia (SWCC), P.O. Box 8328, Al-Jubail 31951, Saudi Arabia

3

evaluation of seawater pretreatment options

1. ${ }^{a}$ King Abdullah University of Science and Technology (KAUST), Water Desalination and Reuse Center (WDRC), Biological and Environmental Sciences \& Engineering Division (BESE),

2. Desalination Technologies Research Institute (DTRI), Saline Water Conversion Corporation

3. Emergent Technologies Institute, U.A. Whitaker College of Engineering, Florida Gulf Coast University, 16301 Innovation Lane, Fort Myers, FL, 33913, United States

\title{
Understanding microbial assembly on seawater reverse osmosis membranes to facilitate
}

Abdullah H.A. Dehwah ${ }^{1,2}$, Hong Cheng ${ }^{1}$, Thomas M. Missimer ${ }^{3^{*}}$, Pei-Ying Hong $^{1 *}$ 


\section{Abstract}

26 Membrane biofouling is the primary cause of inefficiency in seawater reverse osmosis

27 desalination. The identification and subsequent removal of causative microorganisms would

28 therefore be beneficial. To achieve this aim, the assembly of microorganisms onto the reverse

29 osmosis membranes was first modeled to reveal a niche-selective process. Specifically, bacterial

30 genera Hyphomonas, Muricauda, Bacillus and Pseudoruegaria were detected in occurrence

31 frequency higher than predicted, and likely play a role in biofouling due to production of

32 exopolymers. Subsequently, four different pretreatment systems, namely ultrafiltration (UF)

33 membranes, intake wells, dual media filtration (DMF) and cartridge filters (CF), were evaluated

34 for their log removal efficiencies of these four genera. UF outperformed the others in removing

35 the potential biofouling-associated genera, but intake wells achieved a higher log removal of cell

36 densities. Microbial regrowth, as denoted by an increase in cell numbers, was consistently

37 observed within the CF. Using well intakes provides the highest degree of pretreatment in

38 removing total cells in a chemical-free manner, while UF is the next best process to remove

39 bacteria and organic carbon compounds most responsible for membrane biofouling.

42 Keywords: assembly model; biofouling; amplicon sequencing; log removal 


\section{Introduction}

44

Exacerbating rates of global water depletion have incentivized countries to explore seawater desalination as an alternative source for freshwater [1]. Seawater can be converted into freshwater by removing salt content either by means of thermal distillation or membrane-based desalination. Although only about $1 \%$ of the world's current water supply is produced through desalination, it is projected that by 2025 , about $14 \%$ of global water will be provided by desalination [2]. Specifically, desalination by means of seawater reverse osmosis (SWRO) membranes accounts for about $65 \%$ of the global capacity, and will increasingly be adopted by countries that aim to produce desalinated waters for municipal use [2].

Although RO desalination produces high quality potable water, the membranes are generally very sensitive to feedwater quality and are particularly prone to biofouling $[3,4]$. The accumulation of the foulant layer decreases the permeate flux, compromises the overall efficiency of the desalination plant, and hence, requires placing the system offline for membrane cleaning [5]. Even after cleaning the membrane, it was observed that membrane function never recovers to its full effectiveness and tends to further decline with subsequent cleanings [6]. Hence, biofouling has a significant impact on SWRO treatment cost [7].

To mitigate this challenge, various types of pretreatment processes are operated before seawater enters the SWRO membranes $[8,9]$. Larger debris is removed by some type of traveling screen system. Conventional pretreatment systems include dual media filters (DMF) and cartridge filters (CF). Dual media filters (DMF) have differing designs with layers of anthracite, sand, pebbles and gravels to provide physical filtration of the raw seawater [9]. Water flow through can be downwards (most systems) or upwards (Tampa Bay Water SWRO Plant) 
depending on the objectives of the pretreatment system. CF provides for removal of particle sizes

67 of $1,2,5,10$ and $25 \mu \mathrm{m}$, with the most frequently used size being $5 \mu \mathrm{m}$ [9], and occurs directly upstream of the membrane process to protect it from particulate entry. Both types of mixed media filtration can be used with chemical coagulants (e.g. $\mathrm{FeCl}_{3}$ ) to cause particle aggregation to facilitate removal of smaller particles and aggregated bacteria. In some modern pretreatment

71 systems where potential algal blooms occur, a dissolved air flotation (DAF) system can occur

72 after large debris removal. Ferric chloride is commonly added to the inflowing water to cause

73 flocculation of particulate matter. The DAF system is then followed by mixed media filtration 74 and then cartridge filters.

Another pretreatment strategy that works based on physical separation and removal is to use ultrafiltration (UF) to produce water quality that is superior to that obtained from DMF and CF.

77 However, the small pore size associated with UF membranes requires higher energy costs to 78 maintain the needed permeate flux compared to a CF or DMF system. In recent years, subsurface 79 intakes, including wells and seabed galleries, have been used as an alternative environmentally 80 friendly pretreatment system $[10,11]$. Intake wells rely on indigenous geological media to 81 provide physical filtration of particulates, adsorption, and biological degradation of organics in 82 the raw seawater, much like that of DMF and CF. SWRO systems operating with well intakes tend not to use any chemical coagulants $[10,12]$. systems for the changes in the microbial community along the treatment process [13-20]. A more

86 focused evaluation on their overall removal efficacies of bacteria should be made. Specifically, 87 these pretreatment systems should be evaluated for their removal efficiencies of microbial 88 populations that may contribute to the reverse osmosis membrane biofouling. However, it is not 
89 known if the fouling process on SWRO membranes follow a neutral assembly model or a niche

90 selection system. A neutral assembly system assumes a random stochastic process where any

91 microorganisms may contribute to the attachment process, and will be replaced rapidly by

92 another microorganism should it die off or be detached from the biofilm matrix [21, 22]. Hence,

93 no single bacterium plays an important role in the biofouling process. In contrast, a niche

94 selection model presumes that a particular bacterial group outcompetes the others in attaching

95 onto the membrane, hence playing a bigger contribution on the fouling process which was found

96 by some researchers $[23,24]$. The repercussions of determining which model best describes the

97 RO membrane fouling process is that the pretreatment systems can then be evaluated

98 accordingly. For example, if the RO membrane fouling follows a neutral assembly model, then

99 the pretreatment system that achieves the highest log removal for the total cell density, regardless

100 of what type of bacterial population is removed, would be preferable. Alternatively, if the RO

101 membrane fouling follows a niche selection model, a pretreatment system that effectively

102 removes those causative bacterial populations would be more effective in delaying RO

103 membrane fouling. This study therefore aims to first determine the assembly model for a fouled

104 SWRO membrane. Second, the four pretreatment systems, namely, the subsurface seabed, DMF,

105 CF and UF are further evaluated for their removal efficiencies of microbial communities, with

106 emphasis made on log removal of cell counts depending on the outcome of the assembly model. 


\section{Methods}

111

112

113

114

115

116

117

118

\subsection{Sampling sites and pretreatment description}

Four types of pretreatment systems utilized by five different desalination plants located in Saudi Arabia were included for analysis in this study (Fig. 1). The first examined pretreatment systems were intake wells used for seawater reverse osmosis (SWRO) plants located on the Red Sea at the North Obhor (site A), Jeddah Corniche (site B) and South Jeddah Corniche (site C) sites. The detailed description of these three studied sites were provided in an earlier study [10] . The second examined pretreatment system is dual media filter (DMF), used after the subsurface intake wells at site A [10] and in a separate SWRO plant (site D) located on the Red Sea coast in Saudi Arabia [20]. The third examined pretreatment system is micro cartridge filtration, CF, which provides a filtration size ranging from $5 \mu \mathrm{m}$ to $25 \mu \mathrm{m}$. CFs were used at sites A and D after the DMF. A double CF system (the first CF has filtration size of $25 \mu \mathrm{m}$, and the second CF has filtration size of $5 \mu \mathrm{m}$ ) was utilized at site B after the subsurface intake wells. At site $\mathrm{C}, \mathrm{CF}$ was used after UF. The fourth examined pretreatment system was ultrafiltration (UF) utilized by a pilot-scale desalination plant, site E, located in Jubail, Saudi Arabia [15]. UF system in site C was not included for sequencing analysis in this study as site $\mathrm{C}$ has a mesh system preceding the UF that would complicate determination of which bacterial populations were removed solely by UF. More details on the operating parameters of each pretreatment options are provided in Table 1. In addition, fouled RO membranes from $1^{\text {st }}$ and $4^{\text {th }}$ modules of site $\mathrm{E}$ were also sampled for their biomass based on procedures described earlier [15]. Access to fouled RO membranes from the remaining sites were not provided, and therefore not included in this study.

Water samples were collected before and after each type of pretreatment system, and filtered through a $0.4 \mu \mathrm{m}$ Whatman Nucleopore ${ }^{\mathrm{TM}}$ track-etched polycarbonate membrane filter (GE 
133 Healthcare Life Sciences, Little Chalfont, Buckinghamshire, UK). Biomass retained on the 134 polycarbonate filters was stored at $-20^{\circ} \mathrm{C}$ until DNA extraction and $16 \mathrm{~S}$ rRNA gene-based 135 amplicon sequencing.

\subsection{Flow cytometry to determine total cell counts}

Total cells in water samples were determined by flow cytometry either on Accuri C6 or BD FACSVerse (BD Bioscience, NJ, US) based on protocol described previously [10, 15, 20].

139 Briefly, samples were stained with 100X SYBR green (Thermo Fisher Scientific, MA, US) at a 140 volumetric ratio of 100: 1 (i.e., for every $1 \mathrm{~mL}$ of samples, $10 \mathrm{uL}$ of SYBR green was used to 141 stain cells). The suspension was then incubated in $35^{\circ} \mathrm{C}$ and in the dark for 10 min before flow 142 cytometry. $50 \mu \mathrm{L}$ aliquots of stained samples were injected with a $35 \mu \mathrm{L} / \mathrm{min}$ flow rate to 143 enumerate the total cells. Log removal values (LRV) of total cells are calculated based on 144 Equation 1:

\section{---- Equation 1}

\subsection{DNA extraction and $16 \mathrm{~S}$ rRNA gene-based amplicon sequencing} newly performed for this study, while that for sites D and E were performed in earlier studies

$149[15,19,25]$. Specifically, all biomass collected from sites A, B, C and E were extracted using 150 UltraClean ${ }^{\circledR}$ Soil DNA isolation kit (MoBio, Carlsbad, CA, US) based on a modified protocol 151 described earlier [26]. The modified protocol combines enzymatic, chemical and physical lysis to 152 ensure comprehensive extraction of bacteria and archaea that may have different cell wall 153 structures. Samples collected from site D were extracted for DNA by another research group, 154 which although used a different extraction kit, relied on similar combination of enzymatic, 
155 chemical and physical lysis [25]. PCR amplification of the 16S rRNA genes was performed with 156 515F (5' - Illumina overhang- GTGYCAGCMGCCGCGGTAA- 3') and 907R (5' - Illumina 157 overhang- CCCCGYCAATTCMTTTRAGT- 3') for sites A, B, C and E. For site D, PCR 158 amplification of the $16 \mathrm{~S}$ rRNA genes was performed with $27 \mathrm{~F}$ (5'159 AGAGTTTGATCMTGGCTCAG-3') and a reverse primer 519R (5' -

160 GTNTTACNGCGGCKGCTG - 3'). All amplicons were of the anticipated size of approximately $161500 \mathrm{bp}$, and the negative control had no amplification. Samples from sites A, B and C were 162 newly sequenced by KAUST Core lab on Illumina MiSeq for this study. Samples collected from 163 sites D and E were amplicon sequenced as described earlier [15, 20]. All high-throughput 164 sequencing files newly obtained for this study were deposited in the Short Read Archive (SRA) 165 of the European Nucleotide Archive (ENA) under study accession number PRJEB32161.

\subsection{High-throughput sequencing data analysis}

167 Amplicon sequences newly obtained for this study had a Phred score $>30$ and sequencing 168 length >280 nt. Primers, adaptors, and index sequences were removed. All new sequencing data 169 (for sites A to C) and downloaded raw data (for sites D and E) were identified and removed for 170 their chimeras by UCHIME algorithm [27]. Chimera-free sequences were then analyzed through

171 two approaches. The first approach was to analyze for their taxonomical assignment using

172 Ribosomal Database Project (RDP) Classifier at 95\% confidence level with copy number 173 adjustment [28]. Relative abundance at the genus level was calculated for each sample. Absolute 174 abundance of specific genera present in a particular sample is estimated by multiplying the 175 relative abundance of that genus against the total number of cells obtained by flow cytometry for 176 that sample. 
Parallel to the above analysis, chimera-free sequences within a single sample dataset were

178 also aligned for homology against each other based on the Infernal aligner prior to complete

179 linkage clustering [29]. The cluster file is then input into the RDP Pipeline to determine Shannon 180 diversity index $(\mathrm{H})$ and Chaol index.

In the second approach, sequence files were identified as unique operational taxonomic units

182 (OTUs). Briefly, chimera-free sequences were combined with an in-house written Perl script.

183 The combined sequence was then sorted for unique OTUs at 97\% 16S rRNA gene similarity

184 using CD-Hit program to cluster and compare the nucleotide sequences [30]. Relative abundance

185 was calculated. Taxonomy classification was conducted using QIIME open-source

186 bioinformatics pipeline [31] based on RDP database.

187

\subsection{Neutral assembly modeling for seawater reverse osmosis membranes}

To assess the role of neutral process in the assembly of the seawater desalination reverse osmosis membranes, the Sloan neutral model $[21,22]$ was examined to fit the relative abundance of the rarefied OTUs in the untreated seawater and fouled reverse osmosis membranes sampled from site E. All samples were sub-sampled at same sequence depth. After the fitting, OTUs from the pool were subsequently sorted into three partitions depending on whether they occurred more frequently than ('above' partition), within ('neutral' partition), or less frequently than ('below' partition) the $95 \%$ confidence interval of the Sloan neutral model predictions [32]. The taxa above the partition indicates they were actively being selected for, while taxa below the partition indicates that they were actively being selected against. The goodness of fit for the Sloan neutral community model was evaluated using the root mean square error (RMSE) and the generalized $\mathrm{R}$-squared ( $\mathrm{R}^{2}=1$-the sum of squares of residuals/the total sum of squares) [33]. A higher $\mathrm{R}^{2}$ value (maximum value of 1) implies that a neutral process of dispersal and ecological drift 
200 contributes more towards community assembly, whereas a low $\mathrm{R}^{2}$ value (e.g., ca. 0.2) implies

201 poor fitting and other processes (i.e., selective growth/attachment) contributing to the community

202 assembly $[34,35]$.

203

204 3. Results

205 3.1. Fouling of reverse osmosis membranes in SWRO is a niche selected process

206 A neutral assembly model was used to investigate the formation of microbial community on

207 seawater reverse osmosis membranes obtained from site E. The goodness-of-fit $\left(\mathrm{R}^{2}\right)$ value of the

208 model was 0.22 (Fig. 2), and this low $\mathrm{R}^{2}$ value suggested that the microbial community in both

209 the feed stream and biofilm did not follow random migration, but instead was shaped by niche-

210 driven selection. Specifically, the OTUs that were located above the fit of the neutral model

211 (denoted as OTUs in the purple zone, Fig. 2) were present in a frequency higher than that

212 predicted by the model. This suggests that they were identified to occur on the fouled RO

213 membranes at a higher frequency than predicted, and likely to be preferentially selected for by

214 RO membranes to attach onto the surfaces. In contrast, the OTUs that were located below the

215 neutral model (denoted as OTUs in the green zone, Fig. 2) were present in frequency lower than

216 that predicted by the model, suggesting that these OTUs do not attach well on the RO membrane.

217 By comparing the identities of genera associated with these OTUs in both the purple and green

218 zones, and discarding those that appeared in both zones since those would signify ambiguous and

219 contradictory results, it was determined that Hyphomonas, Pseudoruegeria, Bacillus and

220 Muricauda were found consistently located above the model in the purple zone. In particular,

221 Hyphomonas accounted for $27.3 \%$ of the total located in the purple zone (Fig. 2). These 
222 observations suggest that these four genera may contribute more than other genera towards

223 seawater RO membrane fouling.

\subsection{Log removal of RO-selected microbial genera varied across the pretreatment type}

Given that Hyphomonas, Pseudoruegeria, Bacillus and Muricauda were selectively attached on

227 the fouled reverse osmosis membrane and may contribute more towards RO membrane fouling,

228 the upstream pretreatment steps (i.e., intake wells, CF, DMF, and UF) were therefore further

229 evaluated for their log removal values of these four genera (Fig. 3). LRV were determined based

230 on the estimated abundances of individual genera before and after pretreatment. Pseudoruegeria

231 was not detected in samples collected from the pretreatment stages and no LRV could be

232 determined for this genus. The observed removal efficiencies of the different pretreatment

233 methods was UF > intake wells $>$ DMF $>$ CF. UF performed better than all other pretreatment

234 methods, achieving 1.0, 0.2 and $1.3 \log$ removal for Hyphomonas, Bacillus and Muricauda,

235 respectively. Intake wells achieved 0.6 and 0.7-log removal for Hyphomonas and Bacillus, but

236 supported a potential regrowth of Muricauda. In contrast, CF did not provide any removal, and

237 instead resulted in a potential regrowth for all three evaluated genera.

\subsection{Changes in cell abundance and top abundant genera at each sampled site}

A further examination of each stage of the pretreatment system at sites A through $\mathrm{E}$ suggested that intake wells achieved an average $1.0 \log$ LRV of the total cells compared to the

242 other three pretreatment methods (Fig. 4). This reported LRV was comparable to that achieved 243 by UF (0.8-log), and higher than that reported for DMF (0.6-log). Among the four sites that 
244 operate $\mathrm{CF}$, three experienced a positive increase in cell numbers after $\mathrm{CF}$, suggesting a wide

245 variability in CF performance from site to site (Fig. 4). Based on the removal values of the total

246 cell numbers, the top 20 most abundant genera were further examined for their removal

247 efficiencies by the respective pretreatment method (Fig. 3). The intake wells achieved positive

$248 \log$ removal efficiencies of 18 of the top 20 most abundant genera, except for Nitrosopumilus and

249 Nitrososphaera. In contrast, DMF and UF did not achieve positive log removal for 6 to 7 of the

250 top 20 most abundant genera. CF consistently was not able to remove any bacterial genera

251 effectively with the exception of Pseudomonas and Alcanivorax, albeit at very low log removal

$252(<0.4-\log )$.

\subsection{Changes in microbial diversity along the pretreatment train at each site}

Despite a decrease in the total cell numbers, there was an increase in the microbial diversity, 256 as exemplified by both Chao and $\mathrm{H}^{\prime}$ indices, in the waters after passing through the subsurface

257 seabed (Table 2). In contrast, microbial diversity in waters decreased after passing through DMF,

258 CF and UF. Although microbial diversity increases after the intake wells, the total cell numbers

259 decreased by ca. 1-log. This means that the new microbial populations added to the system by

260 the intake wells account for a very low estimated abundance. A further examination of the top 20

261 most abundant genera that were not detected in the seawaters but detected after passing through

262 subsurface seabed revealed that they are mainly indigenous populations associated with the

263 marine environment and well water below the seabed (Table 2). Since the raw well water is held

264 in the storage tanks for variable time periods, the microbial diversity decreased back to a level

265 that approximates that found in the raw seawater (Table 2). 


\section{Discussion}

Biofouling of seawater reverse osmosis is thought to be the major bottleneck in the overall sustainability of membrane-based desalination. Biofouling involves the preconditioning of the membrane and then attachment of primary microbial colonizers onto the membrane surface [36].

271 These microorganisms can secrete extracellular polymeric substances which further condition the

272 membrane surface to facilitate subsequent attachment and buildup of the biofilm layer by

273 secondary colonizers $[37,38]$. Collectively, the biofilm matrix contributes to irreversible foulant

274 layer that may be difficult to eradicate even with chemical cleaning. It is therefore inferred that

275 by identifying the primary colonizers and devising strategies to inhibit their colonization, it

276 would delay biofouling. However, this intervention strategy specifically targeting the primary

277 colonizers or causative microbial agents would only be effective if the biofouling process is 278 dominated by a niche selection process and not by the neutral assembly process.

279 Modeling of 16S rRNA amplicon sequencing data obtained from fouled SWRO membranes 280 in site E suggests that biofouling indeed followed a niche selection process, and was potentially 281 mediated by four main genera, namely Hyphomonas, Muricauda, Bacillus and Pseudoruegeria. 282 Hyphomonas and Muricauda which belong to the class Alphaproteobacteria and Flavobacteria, 283 respectively. Both classes of bacterial populations have been reported on fouled RO membranes 284 in earlier studies. Khan et al. [39] examined in temporal succession the microbial communities 285 developed on SWRO membrane, and found that a 3-week old fouled membrane was almost 286 exclusively represented by Alphaproteobacteria. Similarly, Zhang et al. also reported 61.2\% of 287 the total microbial community on fouled SWRO membranes to be related to

288 Alphaproteobacteria, while Flavobacteria constituted a lower percentage of the microbial 
community compared to Alphaproteobacteria [18]. In another study, the percentage of Alphaproteobacteria on fouled SWRO membranes could range from 73 to $91 \%$ of total microbial community throughout the four seasons in Mediterranean Sea [16]. However, at a finer taxonomical resolution, it was reported that SAR11, and not Hyphomonas spp., accounted for as the main Alphaproteobacteria on the fouled membranes harvested from the desalination plant located in Mediterranean Sea [16]. Neither was Hyphomonas spp. reported to be one of the genera within Alphaproteobacteria recovered from the fouled SWRO membranes harvested from the desalination plants located in Carlsbad, California [18]. This suggests that the four genera reported in this study may not be universal fouling-causing bacterial populations. Instead, they may be playing location-specific roles in fouling of SWRO membranes since all sampled sites included in this study were located in Red Sea.

Nevertheless, this study provides a proof-of-concept of an approach to first determine the assembly process of microorganisms onto SWRO membrane fouling, and then evaluate the pretreatment options for the removal of those microorganisms contributing the most to fouling. For example, in this study, it was elucidated SWRO membrane biofouling follows a niche selective process. The foremost criteria when evaluating the pretreatment options would therefore be the log removal values of Hyphomonas, Muricauda, Bacillus and Pseudoruegeriathe four genera preferentially selected for by RO membranes. In particular, Hyphomonas spp. were found to be very good biofilm formers, typically forming granular aggregates or were found adhered on the walls of glass culture bottles [40]. A similar observation was made for the Flavobacteria which appear to be major bacterial colonizers on transparent exopolymeric particles (TEP) [41]. The concentration of TEP, which comprise extracellular polymeric substances (EPS), correlate to RO membrane fouling in a pilot-scale desalination plant in Saudi 
312 Arabia [42]. This suggests that both Hyphomonas and Muricauda play an important role in the

313 biofouling, likely through exopolymer production that would contribute to increased attachment

314 of other bacteria like Bacillus. Hence, the pretreatment options that achieve the highest log

315 removal values of Hyphomonas and Muricauda - the fouling causative bacteria - would serve to

316 delay RO membrane fouling more effectively than those pretreatment options that achieved only

317 low removal values.

318 However, perhaps concerning is that among all evaluated pretreatment, CF results in

319 microbial regrowth, as denoted by the increase in cell numbers, of most predominant bacterial

320 populations. In an early study [42], the authors attribute this increase in cell numbers to the way

321 pretreatment system was operated - possibly because sodium bisulfate (SBS) was added to

322 quench residual chlorine prior CF and thus deactivated bacteria recover their activity.

323 Alternatively, phosphate-based antiscalant typically used in pretreatment may have enhanced the

324 bioactivity, since phosphate limitation is proposed as a way to control biofouling [43]. Chemical

325 addition was found to also correlate with biofouling potential in the full scale desalination plant.

326 Similarly, chemical addition may also account for regrowth and increase in certain bacterial

327 populations observed in DMF permeate streams. DMF is generally coupled with ferric-based

328 coagulants so that suspended particulates including bacterial contaminants would aggregate and

329 be removed effectively by DMF. It is likely that the iron-based coagulants can also contribute to

330 the regrowth events since the typical concentration of $\mathrm{FeCl}_{3}$ coagulants used are about 0.25 to 5

$331 \mathrm{mg} / \mathrm{L}$ [44]. This is lower than the toxic concentrations of $300 \mathrm{uM}$ (i.e., $180 \mathrm{mg} / \mathrm{L}$ ) determined for

332 Pseudomonas syringae [45]. Low concentrations of iron have also been found to lead to

333 significant increase in Escherichia coli in oligotrophic environment as iron is an essential

334 element for bacteria to sustain its metabolic pathways, amino acids and nucleic acid synthesis 
$335[46,47]$. In contrast, despite the use of the same chemicals in the UF system, regrowth was not

336 apparent in UF permeate likely because the small pore sizes would have rejected these microbes.

337 Alternatively, the intake wells do not require addition of chemicals and yet were able to achieve

338 LRV comparable to that of the UF. Specifically, it was previously demonstrated to result in

339 significant reduction in TEP and organic constituents in the seawater [10, 12]. This minimizes

340 the potential for chemical-induced microbial regrowth events and costs associated with chemical

341 addition. However, it is noted that all of the pretreatment options did not manage to achieve a

342 total removal of both the causative bacterial genera (Figure 3) and total cells (Figure 4), and

343 hence a complete eradication of RO membrane fouling would not be possible. Instead, all the

344 examined pretreatment options, particularly that of UF and intake wells can serve to delay

345 biofouling by achieving high removal values of the causative bacterial genera selected for by the

346 RO membranes.

347 Given the projected needs for freshwater by an increasing exponential rate of population

348 growth, and the exacerbating water scarcity in many arid countries, turning to seawater as a

349 source of drinking water would be increasingly adopted. The use of intake wells and/or UF as an

350 appropriate pretreatment system prior RO can be considered in places where the local geology of

351 the site would permit good removal as is the case observed for sites A through $\mathrm{C}$ in this study.

352

353

354

355 This study demonstrates that certain bacterial populations (e.g. Hyphomonas, Muricauda,

\section{Conclusions}

Pseudoruegeria, Bacillus) are selectively attached on seawater reverse osmosis membranes,

357 likely due to their ability to form an adhesive exopolymer that conditioned the membranes to 
358 facilitate subsequent biofilm formation. Pretreatment systems that achieved high removal values

359 of these four genera are therefore more favorable. It was observed that UF achieved the best

360 removal values for all three bacterial genera followed by intake wells. CF, in contrast, had higher

361 cell counts in the CF permeate, likely due to the use of Fe-based chemical coagulants that

362 supported microbial regrowth and the $>5$ um pore size that does not reject bacterial cells

363 effectively. Despite the good performance of UF in removing the bacterial populations that

364 would detrimentally affect RO, UF by itself is also a membrane and can be prone to fouling.

365 Routine replacement costs for UF units may add on to the operational costs of desalination plants

366 [48], and may not be an optimal option for cost-conscious utilities. Hence, considering the

367 collective information obtained from this study in terms of removal efficiency, associated costs

368 and use of chemicals, intake wells and/or UF may be more optimal options compared to DMF

369 and $\mathrm{CF}$.

370 Acknowledgement

371 This study is funded through KAUST Competitive Research Grant URF/1/2982-01-01 awarded

372 to P.-Y.H. 
373 Table 1. Operating details of pretreatment options at studied sites.

374

\begin{tabular}{|c|c|c|c|}
\hline Site & Pretreatment & Chemicals & Reference \\
\hline $\mathrm{A}$ & $\begin{array}{r}\text { Well intake }+ \text { dual media filter }+ \\
\text { cartridge filter }(5 \mu \mathrm{m})\end{array}$ & $\begin{array}{r}\text { No chlorination, no coagulation, only } \\
\text { antiscalants }\end{array}$ & {$[10]$} \\
\hline B & $\begin{array}{r}\text { Well intake }+ \text { cartridge filter }(25 \\
\mu \mathrm{m})+ \text { cartridge filter }(5 \mu \mathrm{m})\end{array}$ & $\begin{array}{r}\text { No chlorination, no coagulation, only } \\
\text { antiscalants }\end{array}$ & [10] \\
\hline $\mathrm{C}$ & $\begin{array}{l}\text { Well intake }+ \text { mesh filter }(100 \mu \mathrm{m}) \\
+ \text { UF membrane }+ \text { cartridge filter } \\
(25 \mu \mathrm{m})+\text { cartridge filter }(5 \mu \mathrm{m})\end{array}$ & $\begin{array}{r}\text { No chlorination, no coagulation, only } \\
\text { antiscalants, CIP cleaning for UF membrane } \\
\text { with citric acids (once per week) }\end{array}$ & [10] \\
\hline $\mathrm{D}$ & $\begin{array}{l}\text { Dual media filter }+ \text { cartridge filter } \\
\qquad(10 \mu \mathrm{m})\end{array}$ & $\begin{array}{r}\text { Continuous chlorination for intake water, } \\
\text { antiscalants, coagulant, cationic polymeric } \\
\text { flocculant, dechlorination }\end{array}$ & [20] \\
\hline $\mathrm{E}$ & $\begin{array}{r}130 \mu \mathrm{m} \text { strainers }+ \text { UF membrane+ } \\
\text { cartridge filter }(5 \mu \mathrm{m})\end{array}$ & $\begin{array}{r}\text { Chlorination for intake water, antiscalant and } \\
\text { sodium metabisulfite were added, UF } \\
\text { membrane were back washed for } 2 \text { minutes } \\
\text { every hour and it was cleaned with sodium } \\
\text { hypochlorite for } 10-15 \text { min. at every } 24 \text { hours }\end{array}$ & [15] \\
\hline
\end{tabular}

375 
376 Table 2. Diversity indices obtained at different stages of the pretreatment train in Sites A 377 through E.

\begin{tabular}{|c|c|c|c|}
\hline & Chao & $\mathbf{H}^{\prime}$ & $\begin{array}{l}\text { Trend compareap8 } \\
\text { to preceding stage }\end{array}$ \\
\hline \multicolumn{4}{|r|}{379} \\
\hline Seawater & 17600.9 & 4.56 & 380 \\
\hline After well & 21272.3 & 5.31 & $\uparrow$ \\
\hline Holding tank & 24555.4 & 6.13 & 381 \\
\hline After DMF & 20967.5 & 6.17 & 382 \\
\hline \multirow[t]{2}{*}{ After CF } & 20257.0 & 5.59 & $\downarrow$ \\
\hline & & & 383 \\
\hline \multicolumn{4}{|l|}{ Site B } \\
\hline Seawater & 27195.7 & 6.88 & \\
\hline After well & 28616.1 & 7.34 & 385 \\
\hline Holding tank & 24341.3 & 5.97 & $\downarrow$ \\
\hline \multirow[t]{2}{*}{ After CF } & 17371.4 & 5.17 & 386 \\
\hline & & & 387 \\
\hline \multicolumn{4}{|l|}{ Site C } \\
\hline Seawater & 25048.5 & 6.03 & 388 \\
\hline After well & 27733.3 & 6.25 & 389 \\
\hline Holding tank & 26770.6 & 6.46 & $\downarrow$ \\
\hline After UF & 22106.9 & 5.27 & 390 \\
\hline After CF & 22445.3 & 5.60 & 391 \\
\hline Site D & & & 392 \\
\hline $\begin{array}{l}\text { Chlorinated } \\
\text { seawater }\end{array}$ & 4200.1 & 3.98 & 393 \\
\hline After DMF & 721.3 & 3.51 & 394 \\
\hline Site E & & & 395 \\
\hline Seawater & 12640.92 & 5.99 & 396 \\
\hline After UF & 3036.2 & 4.78 & 397 \\
\hline After CF & 1959.9 & 4.40 & $\downarrow$ \\
\hline
\end{tabular}


403 Table 2. Estimated abundance of bacterial genera that were detected in the water sampled after 404 subsurface seabed but were not detected in the original untreated seawater.

\begin{tabular}{|l|r|}
\hline Bacterial genera & $\begin{array}{r}\text { Estimated abundance } \\
\text { (cells/mL) }\end{array}$ \\
\hline Halobaculum & 1.0 \\
\hline Gp16 & 1.0 \\
\hline Rothia & 1.1 \\
\hline Chelativorans & 2.1 \\
\hline Thalassospira & 2.1 \\
\hline Tranquillimonas & 2.5 \\
\hline Unclassified Thaumarchaeota & 2.8 \\
\hline Woesearchaeota Incertae Sedis AR17 & 3.1 \\
\hline Woesearchaeota Incertae Sedis AR16 & 3.4 \\
\hline Proteiniborus & 3.4 \\
\hline Actinomyces & 3.5 \\
\hline Nitratireductor & 3.9 \\
\hline Halolamina & 4.8 \\
\hline Rhodanobacter & 5.2 \\
\hline Woesearchaeota Incertae Sedis AR18 & 5.4 \\
\hline Candidatus Scalindua & 5.9 \\
\hline Halorubrum & 7.2 \\
\hline Unclassified Candidatus Brocadiaceae & 17.2 \\
\hline Spongiibacter & 28.1 \\
\hline Halogeometricum & 58.4 \\
\hline
\end{tabular}


408 Figure 1. Illustration of the pretreatment at all five sites listed in this study. * denotes the point at 409 which water samples were obtained for analysis.

410 Figure 2. Fit of the neutral model. The predicted occurrence frequencies for seawater influent 411 and biofilm community. OTUs that occur more frequently than predicted by the model are 412 shown in purple while those that occur less frequently than predicted are shown in green. The 413 relative abundance of the OTUs in each outlier group were indicated in pie charts. Red dash lines 414 represent $95 \%$ confidence intervals around the model prediction (blue line).

415 Figure 3. Heat map depicting the log removal values of different bacterial groups by the 416 respective pretreatment system.

417 Figure 4. Changes in the cell abundance, denoted as grey circles, determined at different 418 sampling points of Sites A to E. Log removal values achieved by each stage are listed in the 419 tables. Negative LRV denotes an increase in cell density at the treatment system, with higher cell 420 count than that measured at preceding stage.

421

422

423 


\section{References}

[1] G. Amy, N. Ghaffour, Z.Y. Li, L. Francis, R.V. Linares, T. Missimer, S. Lattemann, Membrane-based seawater desalination: Present and future prospects, Desalination, 401 (2017) 16-21.

[2] G. Runte, Seawater and brackish water Desalination - MST052D, in, BCC Research, Wellesley, MA, USA, 2016.

[3] A. Matin, Z. Khan, S.M.J. Zaidi, M.C. Boyce, Biofouling in reverse osmosis membranes for seawater desalination: Phenomena and prevention, Desalination, 281 (2011) 1-16.

[4] T. Nguyen, F.A. Roddick, L. Fan, Biofouling of water treatment membranes: a review of the underlying causes, monitoring techniques and control measures, Membranes (Basel), 2 (2012) 804-840. [5] N. Dhakal, Controlling biofouling in seawater reverse osmosis membrane systems, 2nd ed., CRC Press, Leiden, the Netherlands, 2017.

[6] L.H. Kim, A. Jang, H.W. Yu, S.J. Kim, I.S. Kim, Effect of chemical cleaning on membrane biofouling in seawater reverse osmosis processes, Desalin Water Treat, 33 (2011) 289-294.

[7] N. Ghaffour, T.M. Missimer, G.L. Amy, Technical review and evaluation of the economics of water desalination: Current and future challenges for better water supply sustainability, Desalination, 309 (2013) 197-207.

[8] R. Valavala, J. Sohn, J. Han, N. Her, Y. Yoon, Pretreatment in Reverse Osmosis Seawater Desalination: A Short Review, Environmental Engineering Research, 16 (2011) 205-212.

[9] N. Voutchkov, Pretreatment for reverse osmosis desalination, 1st ed., Elsevier, Amsterdam, the Netherlands, 2017.

[10] A.H.A. Dehwah, T.M. Missimer, Subsurface intake systems: Green choice for improving feed water quality at SWRO desalination plants, Jeddah, Saudi Arabia, Water Res, 88 (2016) 216-224.

[11] T.M. Missimer, N. Ghaffour, A.H.A. Dehwah, R. Rachman, R.G. Maliva, G. Amy, Subsurface intakes for seawater reverse osmosis facilities: Capacity limitation, water quality improvement, and economics, Desalination, 322 (2013) 37-51.

[12] A.H.A. Dehwah, S. Li, S. Al-Mashharawi, H. Winters, T.M. Missimer, Changes in feedwater organic matter concentrations based on intake type and pretreatment processes at SWRO facilities, Red Sea, Saudi Arabia, Desalination, 360 (2015) 19-27.

[13] A. Belila, J. El-Chakhtoura, N. Otaibi, G. Muyzer, G. Gonzalez-Gil, P.E. Saikaly, M.C.M. van Loosdrecht, J.S. Vrouwenvelder, Bacterial community structure and variation in a full-scale seawater desalination plant for drinking water production, Water Res, 94 (2016) 62-72.

[14] L.A. Bereschenko, G.H. Heilig, M.M. Nederlof, M.C. van Loosdrecht, A.J. Stams, G.J. Euverink, Molecular characterization of the bacterial communities in the different compartments of a full-scale reverse-osmosis water purification plant, Appl Environ Microbiol, 74 (2008) 5297-5304.

[15] P.Y. Hong, N. Moosa, J. Mink, Dynamics of microbial communities in an integrated ultrafiltrationreverse osmosis desalination pilot plant located at theArabian Gulf, Desalin Water Treat, 57 (2016) 16310-16323.

[16] A. Levi, E. Bar-Zeev, H. Elifantz, T. Berman, I. Berman-Frank, Characterization of microbial communities in water and biofilms along a large scale SWRO desalination facility: Site-specific prerequisite for biofouling treatments, Desalination, 378 (2016) 44-52.

[17] Z.U. Rehman, M. Ali, H. Iftikhar, T. Leiknes, Genome-resolved metagenomic analysis reveals roles of microbial community members in full-scale seawater reverse osmosis plant, Water Res, 149 (2019) 263271.

[18] M. Zhang, S. Jiang, D. Tanuwidjaja, N. Voutchkov, E.M. Hoek, B. Cai, Composition and variability of biofouling organisms in seawater reverse osmosis desalination plants, Appl Environ Microbiol, 77 (2011) 4390-4398. 
[19] M.T. Khan, C.L. Manes, C. Aubry, J.P. Croue, Source water quality shaping different fouling scenarios in a full-scale desalination plant at the Red Sea, Water Res, 47 (2013) 558-568.

[20] M.T. Khan, P.Y. Hong, N. Nada, J.P. Croue, Does chlorination of seawater reverse osmosis membranes control biofouling?, Water Res, 78 (2015) 84-97.

[21] W.T. Sloan, M. Lunn, S. Woodcock, I.M. Head, S. Nee, T.P. Curtis, Quantifying the roles of immigration and chance in shaping prokaryote community structure, Environ Microbiol, 8 (2006) 732740.

[22] W.T. Sloan, S. Woodcock, M. Lunn, I.M. Head, T.P. Curtis, Modeling taxa-abundance distributions in microbial communities using environmental sequence data, Microb Ecol, 53 (2007) 443-455.

[23] I.S. Kim, J. Lee, S.J. Kim, H.W. Yu, A. Jang, Comparative pyrosequencing analysis of bacterial community change in biofilm formed on seawater reverse osmosis membrane, Environ Technol, 35 (2014) 125-136.

[24] J. Lee, X. Ren, H.-W. Yu, S.-J. Kim, I.S. Kim, Membrane Biofouling of Seawater Reverse Osmosis Initiated by Sporogenic Bacillus Strain, Environmental Engineering Research, 15 (2010) 141-147. [25] C.L.d.O. Manes, N. West, S. Rapenne, P. Lebaron, Dynamic bacterial communities on reverseosmosis membranes in a full-scale desalination plant, Biofouling, 27 (2011) 47-58.

[26] P.Y. Hong, E. Wheeler, I.K. Cann, R.I. Mackie, Phylogenetic analysis of the fecal microbial community in herbivorous land and marine iguanas of the Galapagos Islands using 16S rRNA-based pyrosequencing, ISME J, 5 (2011) 1461-1470.

[27] R.C. Edgar, B.J. Haas, J.C. Clemente, C. Quince, R. Knight, UCHIME improves sensitivity and speed of chimera detection, Bioinformatics, 27 (2011) 2194-2200.

[28] Q. Wang, G.M. Garrity, J.M. Tiedje, J.R. Cole, Naive Bayesian classifier for rapid assignment of rRNA sequences into the new bacterial taxonomy, Appl Environ Microb, 73 (2007) 5261-5267.

[29] J.R. Cole, Q. Wang, E. Cardenas, J. Fish, B. Chai, R.J. Farris, A.S. Kulam-Syed-Mohideen, D.M. McGarrell, T. Marsh, G.M. Garrity, J.M. Tiedje, The Ribosomal Database Project: improved alignments and new tools for rRNA analysis, Nucleic Acids Res, 37 (2009) D141-D145.

[30] W. Li, A. Godzik, Cd-hit: a fast program for clustering and comparing large sets of protein or nucleotide sequences, Bioinformatics, 22 (2006) 1658-1659.

[31] J.G. Caporaso, J. Kuczynski, J. Stombaugh, K. Bittinger, F.D. Bushman, E.K. Costello, N. Fierer, A.G. Pena, J.K. Goodrich, J.I. Gordon, G.A. Huttley, S.T. Kelley, D. Knights, J.E. Koenig, R.E. Ley, C.A. Lozupone, D. McDonald, B.D. Muegge, M. Pirrung, J. Reeder, J.R. Sevinsky, P.J. Turnbaugh, W.A. Walters, J. Widmann, T. Yatsunenko, J. Zaneveld, R. Knight, QIIME allows analysis of high-throughput community sequencing data, Nat Methods, 7 (2010) 335-336.

[32] A.R. Burns, W.Z. Stephens, K. Stagaman, S. Wong, J.F. Rawls, K. Guillemin, B.J. Bohannan, Contribution of neutral processes to the assembly of gut microbial communities in the zebrafish over host development, ISME J, 10 (2016) 655-664.

[33] O. Ostman, S. Drakare, E.S. Kritzberg, S. Langenheder, J.B. Logue, E.S. Lindstrom, Regional invariance among microbial communities, Ecol Lett, 13 (2010) 118-127.

[34] A. Venkataraman, C.M. Bassis, J.M. Beck, V.B. Young, J.L. Curtis, G.B. Huffnagle, T.M. Schmidt, Application of a neutral community model to assess structuring of the human lung microbiome, MBio, 6 (2015) e02284-02214.

[35] F. Ling, R. Whitaker, M.W. LeChevallier, W.-T. Liu, Drinking water microbiome assembly induced by water stagnation, The ISME journal, 12 (2018) 1520.

[36] H.C. Flemming, Reverse osmosis membrane biofouling, Exp Therm Fluid Sci, 14 (1997) 382-391.

[37] A. Jain, N. Bhosle, Biochemical composition of the marine conditioning film: implications for bacterial adhesion, Biofouling, 25 (2009) 13-19. 
[38] H. Winters, T.H. Chong, A.G. Fane, W. Krantz, M. Rzechowicz, N. Saeidi, The involvement of lectins and lectin-like humic substances in biofilm formation on RO membranes - is TEP important?, Desalination, 399 (2016) 61-68.

[39] M.T. Khan, C.L.D. Manes, C. Aubry, L. Gutierrez, J.P. Croue, Kinetic Study of Seawater Reverse Osmosis Membrane Fouling, Environ Sci Technol, 47 (2013) 10884-10894.

[40] R.M. Weiner, M. Melick, K. O'Neill, E. Quintero, Hyphomonas adhaerens sp nov.. Hyphomonas johnsonii sp nov and Hyphomonas rosenbergii sp nov., marine budding and prosthecate bacteria, Int J Syst Evol Micr, 50 (2000) 459-469.

[41] M. Simon, H.P. Grossart, B. Schweitzer, H. Ploug, Microbial ecology of organic aggregates in aquatic ecosystems, Aquat Microb Ecol, 28 (2002) 175-211.

[42] S. Li, S. Sinha, T. Leiknes, G.L. Amy, N. Ghaffour, Evaluation of potential particulate/colloidal TEP foulants on a pilot scale SWRO desalination study, Desalination, 393 (2016) 127-134.

[43] J.S. Vrouwenvelder, F. Beyer, K. Dahmani, N. Hasan, G. Galjaard, J.C. Kruithof, M.C.M. van Loosdrecht, Phosphate limitation to control biofouling, Water Res, 44 (2010) 3454-3466.

[44] K. Gaid, A large review of the pretreatment, in: R. Ying (Ed.) Expanding issues in desalination, IntechOpen 2011.

[45] B.J. Kim, J.H. Park, T.H. Park, P.A. Bronstein, D.J. Schneider, S.W. Cartinhour, M.L. Shuler, Effect of Iron Concentration on the Growth Rate of Pseudomonas syringae and the Expression of Virulence Factors in hrp-Inducing Minimal Medium, Appl Environ Microb, 75 (2009) 2720-2726.

[46] B.M.R. Appenzeller, C. Yanez, F. Jorand, J.C. Block, Advantage provided by iron for Escherichia coli growth and cultivability in drinking water, Appl Environ Microb, 71 (2005) 5621-5623.

[47] D. Grandjean, F. Jorand, H. Guilloteau, J.C. Block, Iron uptake is essential for Escherichia coli survival in drinking water, Lett Appl Microbiol, 43 (2006) 111-117.

[48] P.H. Wolf, S. Siverns, S. Monti, UF membranes for RO desalination pretreatment, Desalination, 182 (2005) 293-300. 

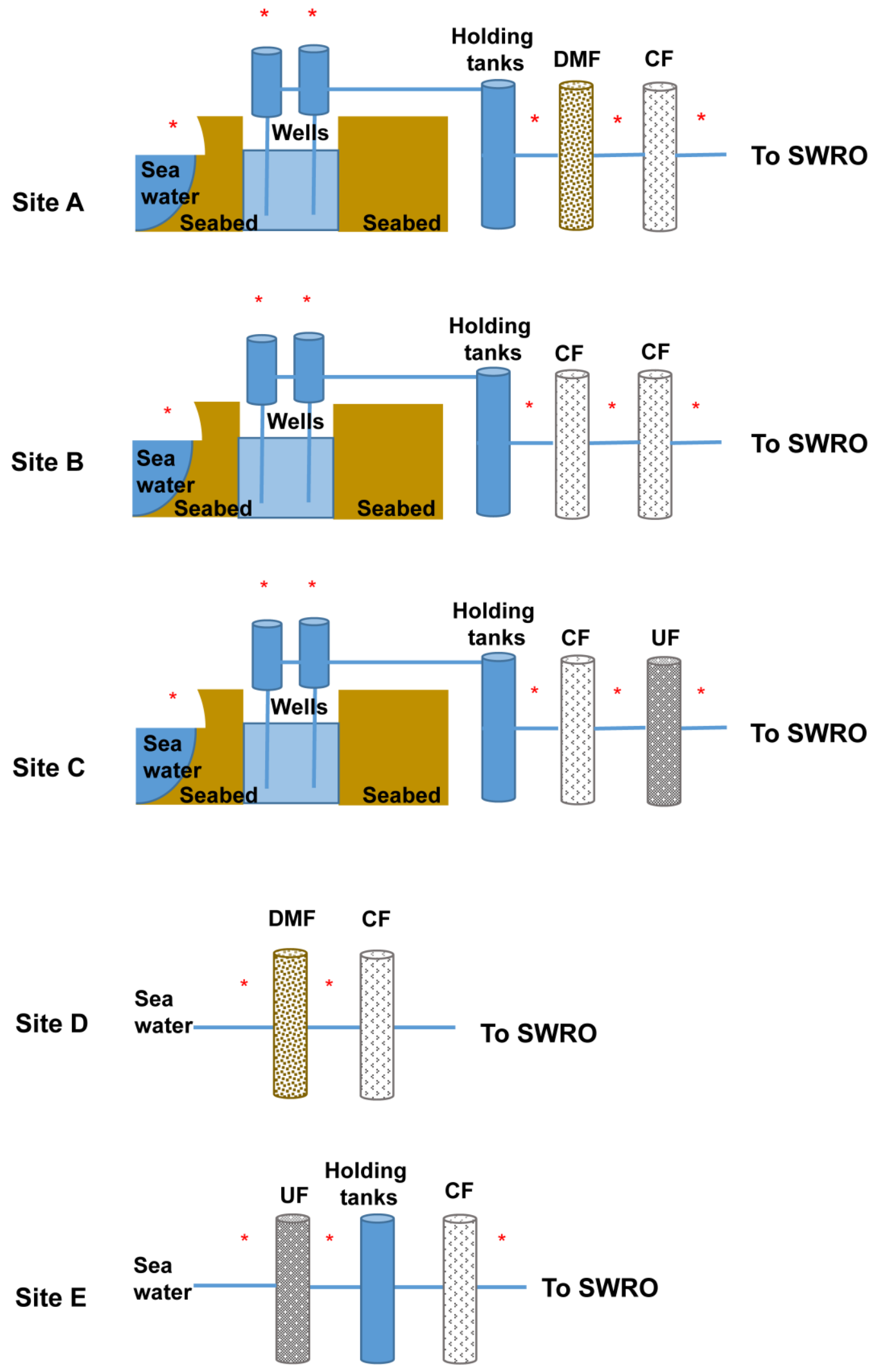


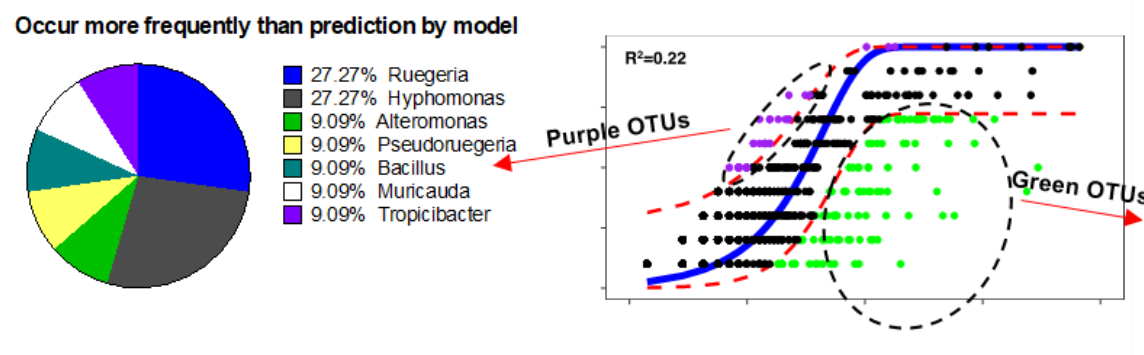

Occur less frequently than prediction by model

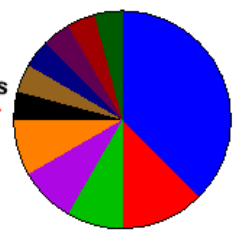

$37.50 \%$ Ruegeria

$12.50 \%$ Pedobacter

$8.33 \%$ Alteromonas

$8.33 \%$ Tropicibacter

$8.33 \%$ Pseudomonas
$4.17 \%$ Acinetobacter

$4.17 \%$ Acinetobacter
$4.17 \%$ Paenibacillus

$4.17 \%$ Curvibacter

$4.17 \%$ Kerstersia

$4.17 \%$ Legionella

$4.17 \%$ Roseivirga 
Log removal values

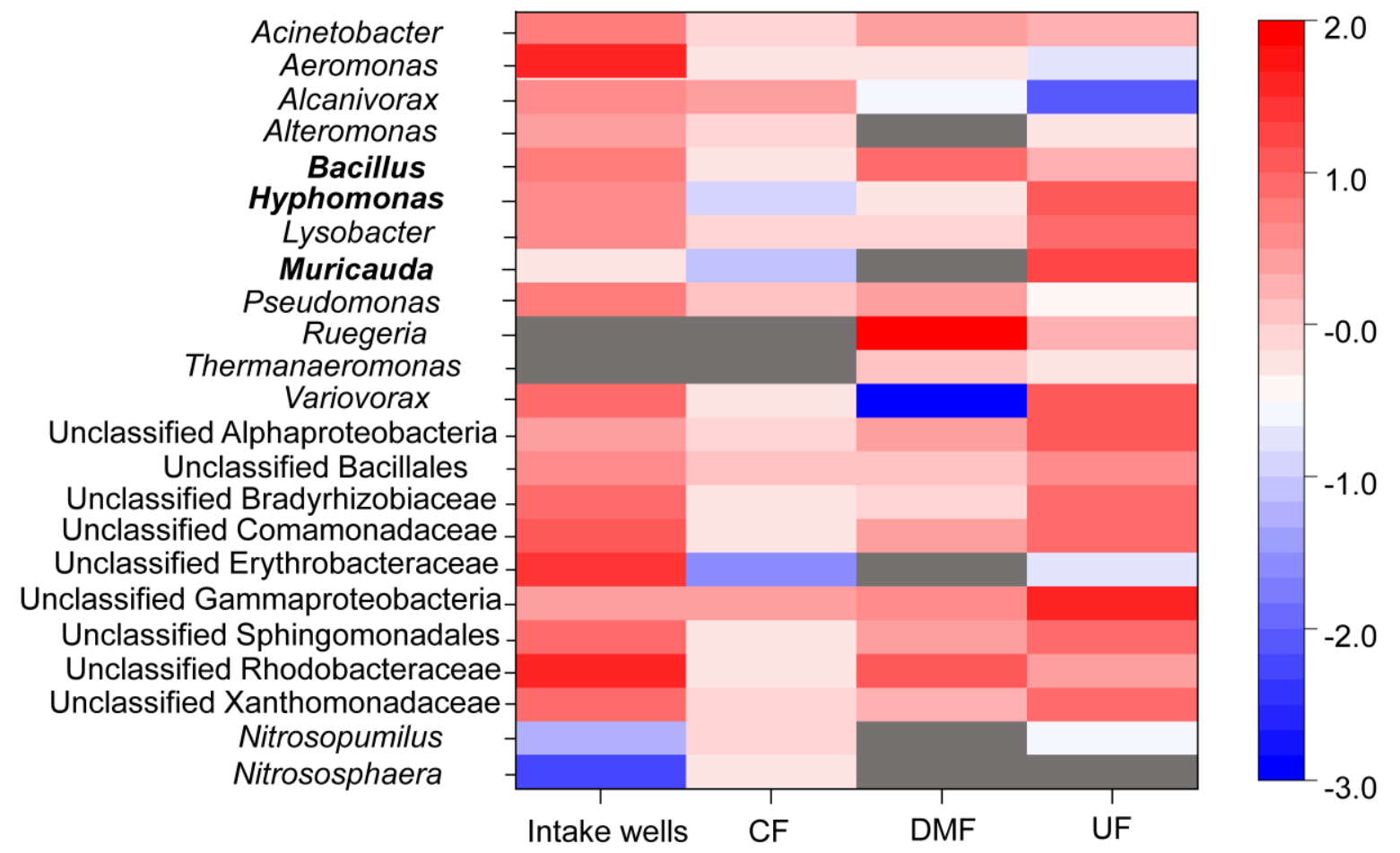


Site A

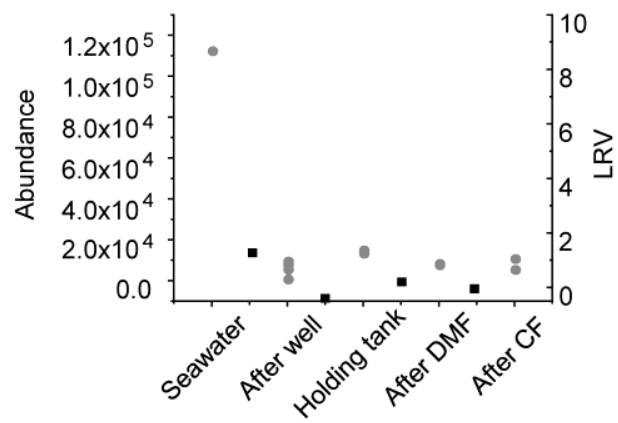

Site B

Site C
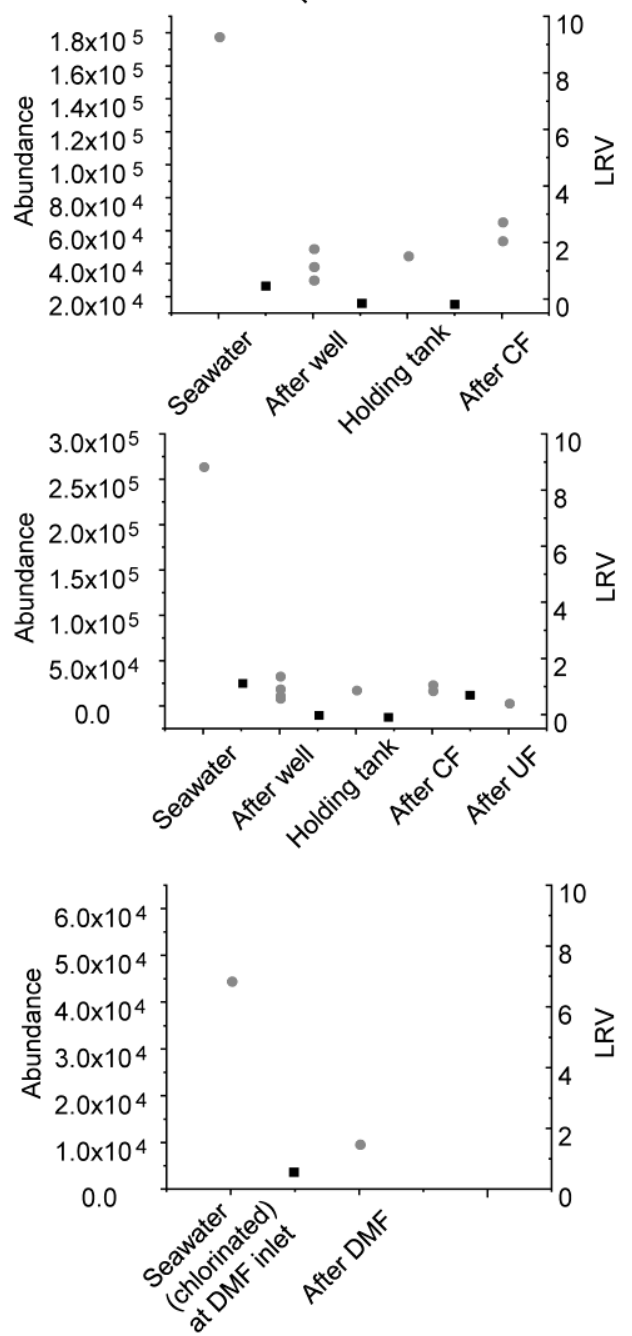

Site E

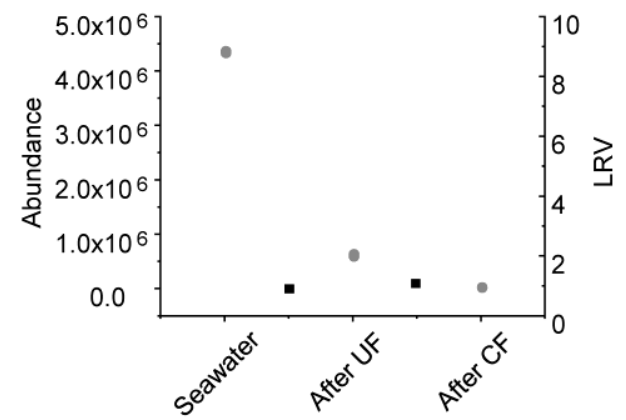

